This journal is the official publication of Bangladesh Society of Physiologists (BSP)

Web URL: www.banglajol.info/index.php/JBSP

Abstracted/indexed in Index Copernicus, Director of Open Access Journal, HINARI Index Medicus for South East Asia Region, Google Scholar, 12OR, infobse index, Open J gate, Cite factor, Scientific indexing services

pISSN-1983-1213; e-ISSN-2219-7508

\title{
Erratum
}

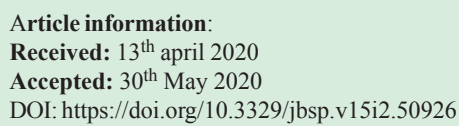

This article is open access licensed under CC BY NC SA which allows readers copy, distribute, display, and perform the work and make derivative works based on it only for noncommercial purposes.

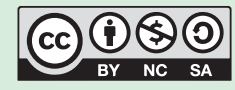

Erratum: Role of blood cells in diagnosis of asthma-COPD overlap among patients with COPD. J Bangladesh Soc Physiol 2020;15(1): 33-38

The author of this article brought attention to publishers that there were errors on page 1,3,4,5 published in previous issue. These errors have been corrected to enhance credibility to readers and the whole corrected article has been published in this issue of JBSP.

The online version of the original article can be found at doi:https://doi.org/10.3329/jbsp.v15i1.48114

\section{Role of blood cells in diagnosis of asthma -COPD overlap among patients with COPD}

\author{
Md. Monimul Islam¹, Md. Ali Hossain², Kazi Saifuddin \\ Bennoor ${ }^{2}$, Taskina $\mathrm{Ali}^{3}$ \\ 1. Department of Physiology, Rajshahi Medical College, Rajshahi. \\ 2. Department of Respiratory Medicine, National Institute of Diseases of the \\ Chest and Hospital, Dhaka \\ 3. Department of Physiology, Bangabandhu Sheikh Mujib Medical University, \\ Dhaka.
}

\section{Abstract}

Background: As asthma-COPD overlap (ACO) and COPD share some common clinical features, this makes difficult to distinguish them from each other. Since, both of them are characterized by airway inflammation, any inflammatory biomarker such as total count (TC) of white blood cells (WBC), neutrophil, eosinophil and platelet can be used for that purpose. Objective: To assess the role of TC of WBC, neutrophil, eosinophil and platelet in diagnosis of ACO among patients with COPD. Methods: This cross sectional study was conducted in the Department of Physiology, Bangabandhu Sheikh Mujib Medical University, Dhaka from 2019 March to Feb 2020. In this study, 63 male stable patients (age range: 40 to 80 years) of COPD were enrolled. Among them, 51 patients were finally selected according to exclusion criteria and divided into two 


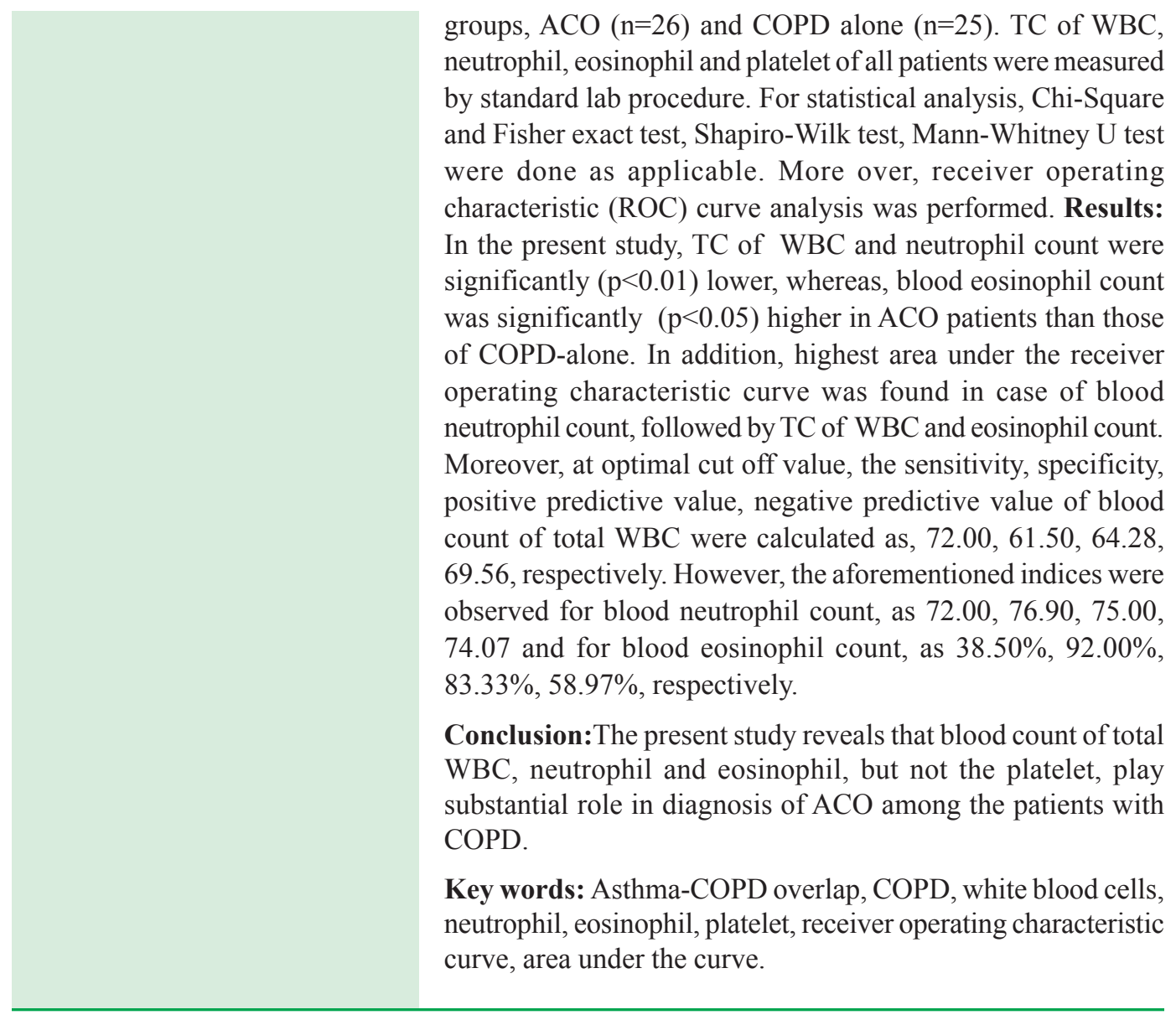

Introduction

sthma and chronic obstructive
pulmonary disease (COPD) are
common obstructive airway diseases, charac-terized by chronic airway inflammation. In COPD, there is persistent airflow limitation, which is usually progressive. ${ }^{1}$ Whereas, in asthma, there is wheeze, shortness of breath, chest tightness, cough that vary in intensity over time with variable airflow limitation. ${ }^{2}$

However, there is ample of evidence that these two distinct disease entities often overlap, ${ }^{3}$ where, approximately one in four patients with COPD present with asthmatic features ${ }^{4}$ and some asthmatics present with fixed airway obstruction. ${ }^{5}$ Recently a joint committee of Global Initiative for Asthma (GINA) and Global
Initiative for Chronic Obstructive Lung Disease (GOLD) recommended the term 'asthma-COPD overlap (ACO)', which does not describe a single disease entity, rather it includes patients with several different forms (phenotypes) of diseases of respiratory tract caused by different underling mechanisms. ${ }^{6}$

Although both ACO and COPD, cannot be cured permanently, their morbidity and progression can be reduced by appropriate treatment. As per treatment protocol proposed by GINA-GOLD joint document, inhaled corticosteroids(ICS) should be included in $\mathrm{ACO}^{6}$, whereas its responsiveness is limited in COPD-alone. ${ }^{1}$ Moreover, it has been reported that treatment with ICS is associated with higher risk of pneumonia in patients with COPD. ${ }^{7}$ For this reason, there is

Volume 15 No. 2 December 2020: 108-114 
utmost importance for proper identification and clear differentiation between these two obstructive airway diseases.

However, in both $\mathrm{ACO}^{8}$ and $\mathrm{COPD}^{9,10}$, systemic inûammation might accompany the local airway inflammation stimulating hematopoietic system, speciûcally bone marrow, resulting in release of different leukocytes and platelets into the blood. $^{11}$

Since, some clinical features of both ACO and COPD without asthmatic components are common to each other, including spirometric findings of post bronchodilator FEV1/FVC ratio $<0.70^{6}$, it is difficult to diagnose this newer respiratory phenotype among the patients with COPD. However, in recent days clinicians only rely on thorough clinical and spirometric evaluation for this purpose. But, both of these approaches are subjective. So, measurement of some objective inflammatory biomarkers, like blood count of total WBC, neutrophil, eosinophil and platelet might aid in correct identification of these inflammatory airway diseases, which are simple and easily obtainable from routinely donecost-effective investigations. Therefore, on the basis of this background the present study was designed to evaluate the role of blood count of total WBC, neutrophil, eosinophil and platelet, in diagnosis of ACO among patients with COPD.

\section{Methods}

This cross sectional study was conducted from March 2019 to February 2020 at Department of Physiology, Bangabandhu Sheikh Mujib Medical University (BSMMU). In our study, 63 male stable patients (age 40 to 80 years; BMI 18.6 to $24.9 \mathrm{~kg} / \mathrm{m}^{2}$ ) of COPD were purposively enrolled from the Out Patient Department (OPD) of BSMMU and National Institute of Diseases of the Chest and Hospital (NIDCH). All patients were diagnosed by pulmonologists according to the GOLD criteria ${ }^{1}$, i.e. post bronchodilator FEV1/FVC ratio $<0.70$. Among them, physician diagnosed patients with any other pulmonary disease, ischemic heart disease, inflammatory bowel disease, inflammatory musculoskeletal disorder, any hematologic or endocrine disorder, any malignancy, uncontrolled systemic hypertension, diabetes mellitus,dyslipidemia, hepatic dysfunction or renal insufficiency, were excluded. Moreover, patients with history of consuming systemic corticosteroid (within 4 weeks prior to study), as well as if they were current smoker, were also excluded from this study. Ultimately, 51 patients were selected and informed written consent was taken from all of them. The protocol of this study involving humanapproved by Institutional Review Board (IRB) of BSMMU, which followed the ethical rule of Helsinki. ${ }^{12}$

After final selection, all COPD patients were divided into two groups, ACO $(n=26)$ and COPD-alone ( $\mathrm{n}=25)$, according to the syndromic approach for diagnosis of ACO proposed by GINA-GOLD joint committee. ${ }^{6}$

As inflammatory biomarker, blood count of total WBC, neutrophil, eosinophil and platelet were measured by Fluorescence Flow Cytometry method using Sysmex XN-2000 (Sysmex America, Inc. USA) CBC analyzers.

The data were expressed as mean with standard deviation (mean $\pm \mathrm{SD}$ ), median with interquartile range and number with percentage. Here, to compare the qualitative data, Chi-Square and Fisher exact tests were done. In addition, to check the normal distribution of quantitative data, Shapiro-Wilk test was done. Then, independent sample ' $t$ ' test was performed to compare normally distributed quantitative data. However, in case of the data showing skewed distribution, log transformation followed by Shapiro-Wilk test were performed. If still they were in skewed distribution, Mann-Whitney U test was done to compare them. Moreover, to determine area under the receiver operating characteristic (ROC) curve (AUC) and optimal cutoff values, ROC curve analysis was performed. All statistical analysis was done using SPSS (Version 23) for Windows. In the interpretation of results, $p$ value $\leq 0.05$ was accepted as significant. 
Results

The general characteristics of the study patients are shown in Table I. No statistically significant difference of those characteristics was found between two groups of patients with ACO and COPD-alone.

In the present study, as shown in Table II, blood count of total WBC and neutrophil were significantly $(\mathrm{p}<0.01)$ lower, whereas, blood eosinophil count was significantly $(p<0.05)$ higher in ACO patients than that of COPD-alone (Table II). However, there was no statistically significant difference of blood platelet count in between two groups (Table II).

As shown in Figure 1, ROC curve analysis demonstrated that AUC of blood count of total WBC, neutrophil and eosinophil were 0.722 $(\mathrm{p}<0.01 ; 95 \%$ confidence interval 0.583-0.862), 0.781 ( $\mathrm{p}<0.01 ; 95 \%$ confidence interval 0.654 $0.908)$ and $0.684(\mathrm{p}<0.05 ; 95 \%$ confidence interval 0.538-0.830), respectively. In addition, to get the best diagnostic accuracy, the optimal cutoff values (according to highest Youden'sindex $)^{13}$ of above mentioned three variables were found as, $9.75 \times 10^{3} / \mu \mathrm{L}, 7.6 \times 10^{3} /$ $\mu$ Land 527.5 cells $/ \mu \mathrm{L}$, respectively.Moreover, at these corresponding optimal cutoff values, the sensitivity, specificity, positive predictive value and negative predictive value of blood count of total WBC were, 72.00, 61.50, 64.28 and 69.56; of blood neutrophil count were, 72.00, 76.90, 75.00 and 74.07; and of blood eosinophil count were, $38.50 \%, 92.00 \%, 83.33 \%$ and $58.97 \%$, respectively (Table III).

Table I: Baseline characteristics of study patients $(\mathrm{N}=51)$

\begin{tabular}{lccc}
\hline Variables & $\begin{array}{c}\text { Patients with ACO } \\
(\mathrm{n}=26)\end{array}$ & $\begin{array}{c}\text { Patients with COPD-alone } \\
(\mathrm{n}=25)\end{array}$ & p value \\
\hline Age $(\text { years })^{\mathrm{a}}$ & $56.9 \pm 10.6$ & $61.6 \pm 9.8$ & $0.103^{\alpha}$ \\
& $(40-75)$ & $(45-80)$ & \\
Weight $(\mathrm{kg})^{\mathrm{a}}$ & $60.4 \pm 4.8$ & $57.4 \pm 5.8$ & $0.051^{\alpha}$ \\
& $(48-68)$ & $(46-69)$ & \\
Height $(\mathrm{cm})^{\mathrm{a}}$ & $168.0 \pm 8.1$ & $165.0 \pm 6.3$ & $0.276^{\alpha}$ \\
& $(154-185)$ & $(154-177)$ & \\
BMI $\left(\mathrm{kg} / \mathrm{m}^{2}\right)^{\mathrm{b}}$ & 21.3 & 20.4 & $0.317^{\beta}$ \\
& $(20.1-22.9)$ & $(19.2-22.4)$ & \\
Smoking status & & & \\
- $\quad$ Never smoker & $5(19.2 \%)$ & $2(8.0 \%)$ & $0.419^{\gamma}$ \\
- Ex smoker & $21(80.8 \%)$ & $23(92.0 \%)$ & $0.254^{\alpha}$ \\
- $\quad$ Pack-years (year) & $25.38 \pm 12.58$ & $29.13 \pm 8.74$ & $0.743^{\mathrm{a}}$ \\
ICS Use $^{\mathrm{c}}$ & $7(26.9 \%)$ & $5(20 \%)$ & \\
\hline
\end{tabular}

Data are shown as mean $\pm \mathrm{SD}$ (a), median (interquartile range) (b) and number (percentage) (c). Statistical analysis was done by independent sample ' $t$ ' test $(\alpha)$, Mann-Whitney U test $(\beta)$, Fisher exact test $(\gamma)$, Chi-Square test $(\delta)$. $\mathrm{N}=$ total number of patients; $\mathrm{n}=$ number of patients in each group; $\mathrm{ACO}=$ asthma-COPD overlap; $\mathrm{BMI}=$ body mass index; pack-year $=($ number of cigarette smoked per day/20) $\mathrm{X}$ number of year smoked; ICS $=$ inhaled corticosteroids. 
Table II: Blood cell count in study patients $(\mathrm{N}=51)$

\begin{tabular}{lccc}
\hline Blood cell & ACO patients $(\mathrm{n}=26)$ & COPD-alone patients $(\mathrm{n}=25)$ & $\mathrm{p}$ value \\
\hline Total WBC $\left(\mathrm{X} 10^{3} / \mu \mathrm{L}\right)$ & 9.5 & 11.0 & $0.006^{* *}$ \\
& $(7.4-11.1)$ & $(9.0-15.2)$ & \\
Neutrophil $\left(\mathrm{X} 10^{3} / \mu \mathrm{L}\right)$ & $5.9(3.8-7.6)$ & $8.1(6.5-11.5)$ & $0.001^{* *}$ \\
Eosinophil $(\mathrm{cells} / \mu \mathrm{L})$ & 350.0 & 270.0 & $0.024^{*}$ \\
& $(254.0-953.0)$ & $(92.5-388.0)$ & \\
Platelet $\left(\mathrm{X} 10^{9} / \mu \mathrm{L}\right)$ & 300.0 & 350.0 & 0.073 \\
& $(266.0-340.0)$ & $(275.0-385.0)$ & \\
\hline
\end{tabular}

Data are shown as median (interquartile range). Statistical analysis was done by Mann- Whitney $\mathrm{U}$ test. $\mathrm{N}=$ total number of patients; $\mathrm{n}=$ number of patients in each group; ACO = asthma-COPD overlap; ** = statistically significant $(\mathrm{p}<0.01) ; *$ statistically significant $(\mathrm{p}<0.05)$

A

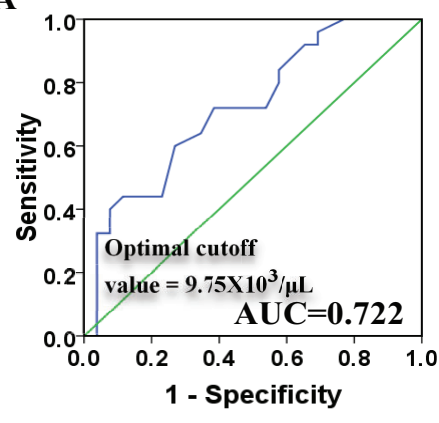

B

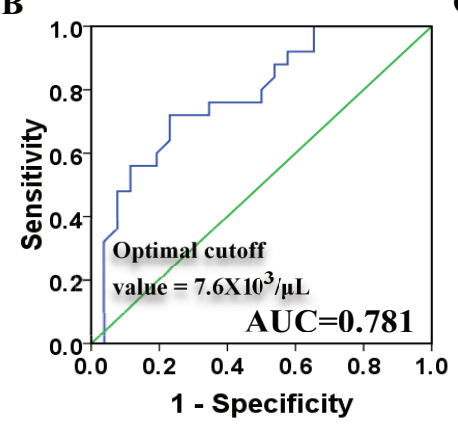

C

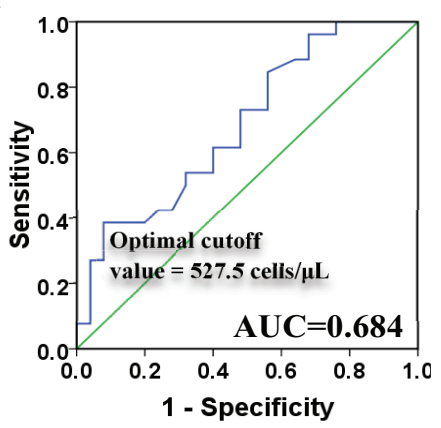

Figure 1: ROC curve of blood total count of WBC (A), neutrophil count (B) and eosinophil count (C) for diagnosis of $\mathrm{ACO}$ among $\mathrm{COPD}$ patients. $\mathrm{ROC}=$ receiver operating characteristic; $\mathrm{AUC}=$ area under the curve

Table III: Diagnostic performance indices of blood cell count at optimal cutoff values

\begin{tabular}{lccc}
\hline Indices(in \%) & $\begin{array}{c}\text { TotalWBC } \\
\left.\text { (at } 9.75 \times 10^{3} / \mu \mathrm{L}\right)\end{array}$ & $\begin{array}{c}\text { Neutrophil } \\
\left(\text { at } 7.6 \times 10^{3} / \mu \mathrm{L}\right)\end{array}$ & $\begin{array}{c}\text { Eosinophil } \\
\text { (at } 527.5 \text { cells } / \mu \mathrm{L})\end{array}$ \\
\hline Sensitivity & 72.00 & 72.00 & 38.50 \\
Specificity & 61.50 & 76.90 & 92.00 \\
Positive predictive value & 64.28 & 75.00 & 83.33 \\
Negative predictive value & 69.56 & 74.07 & 58.97 \\
\hline
\end{tabular}

Discussion

In the present study, blood count of total WBC and neutrophil were significantly lower in our ACO patients compared to that of COPD-alone, indicating their supportive role in distinguishing these two obstructive airway diseases from each other (Table II). To the best of our knowledge this is the first study demonstrating their potential role in diagnosis of ACO among the patients with COPD.

Volume 15 No. 2 December 2020: 108-114
It has been reported that, frequency of ACO was more ${ }^{14}$, whereas, intensity of inflammation was less ${ }^{15}$ in biomass smoke-induced COPD than that of tobacco smoke-induced COPD in Spanish population. These reports might infer that inflammation severity would be less in ACO than that of COPD-alone. Moreover, the increment of blood pro-inflammatory cytokines occurs in higher degree of inflammation ${ }^{10}$, resulting in profound bone marrow stimulation for 
production of leucocytes including neutrophil ${ }^{16}$. Therefore, lower grade of inflammation severity in ACO might explain the findings of lower count of total WBC and neutrophil count in our ACO patients than that of COPD-alone.

In addition to the above mentioned biomarkers, blood eosinophil count was significantly higher in our ACO patients compared to that of COPDalone, indicating their supportive role in diagnosis of ACO among the patients with COPD. Similar observation was reported by different researchers abroad ${ }^{17,18}$.Since, patients with ACO has asthmatic component characterized by type 2 helper T-cell (Th2) mediated inflammation ${ }^{19}$ along with neutrophilic invasion in the airways of $\mathrm{COPD}^{20}$, there is release of different $\mathrm{Th} 2$ inflammatory mediators. Among them, IL-5 increases the differentiation and maturation of eosinophils in bone marrow resulting in high blood eosinophil count ${ }^{21}$.

Moreover, in our study ROC curve analysis showedhighest area under the ROC curve in case of blood neutrophil count, followed by count of total WBC and eosinophil. These observations indicate good diagnostic accuracy of neutrophil count and total count of WBC, as well as sufficient diagnostic accuracy of blood eosinophil count for diagnosis of ACO among patients with $\mathrm{COPD}^{22}$. Few researchers abroad reported similar accuracy of blood eosinophil count ${ }^{17,18}$ for diagnosis of ACO among the patients with COPD.

However, at optimal cutoff values of blood neutrophil count, total count of WBC and eosinophil count, the sensitivity and negative predictive value were found $<80 \%$ (Table III), indicating more chance of false negative result. Whereas, the specificity and positive predictive value were found $>80 \%$ for blood eosinophil count, indicating least chance of false positive result by using it in diagnosing ACO among patients with COPD. However, no study was found to support these findings.
Conclusion

The present study reveals that, blood count of total WBC, neutrophil and eosinophil can play substantial role in diagnosis of ACO among the stable patients with COPD.

However, there were some limitations in our study. Since, counts of blood cells can be affected by parasitic infestations, food allergy, drug allergy, atopic dermatitis, hypereosinophilic syndrome, any vasculitis and airway inflammation can be affected by ICS medication, stable patients of COPD with these comorbidities and those with ICS medication should be excluded. But it could not be possible for unavailability of patients.

Conflict of interest: None.

\section{References}

1. Global Initiative for Chronic Obstructive Lung Disease. Global strategy for the diagnosis, management and prevention of COPD 2019 [Internet] [Cited April 22, 2019]. Available from: http//www.goldcopd.org/ [updated 2019].

2. Global Initiative for Asthma. Global strategy for asthma management and prevention 2019 [Internet] [Cited April 22, 2019]. Available from: http:// www.ginasthma.org.

3. Gibson PG, Simpson JL. The overlap syndrome of asthma and COPD: what are its features and how important is it? Thorax 2009; 64(8):728-735. DOI:10.1136/thx.2008.108027.

4. Sin DD. Asthma-COPD overlap syndrome: what we know and what we don't. Tuberc Respir Dis 2017; 80(1):11-20. DOI:10.4046/trd.2017. 80.1.11.

5. Kim SR, Rhee YK. Overlap between asthma and COPD: where the two diseases converge. Allergy Asthma Immunol Res 2010; 2(4):209-214. DOI:10.4168/aair.2010.2.4.209.

6. Global Initiative for Asthma, Global Initiative for Chronic Obstructive Lung Disease. Global strategy for asthma management and prevention 2019 [Internet] [Cited April 22, 2019]. Available from: http:// www.ginasthma.org.

7. Singh S, Amin AV, Loke YK. Long-term use of inhaled corticosteroids and the risk of pneumonia in chronic obstructive pulmonary disease: a meta-analysis. Arch

Volume 15 No. 2 December 2020: 108-114 
Intern Med 2009; 169(3):219-229. DOI:10.1001/

archinternmed.2008.550.

8. Girdhar A, Kumar V, Singh A, Menon B, Vijayan VK. Systemic inflammation and its response to treatment in patients with asthma. Respir Care 2011; 56(6):800805. DOI:10.4187/respcare. 00601.

9. Eid AA, Ionescu AA, Nixon LS, Lewis-Jenkins V, Matthews SB, Grifûths TL, Shale DJ. Inûammatory response and body composition in chronic obstructive pulmonary disease. Am J Respir Crit Care Med2001; 164:1414-1418. DOI:10.1164/rccm2008109.

10. Agusti AGN, Noguera A, Sauleda J, Sala E, Pons J, Busquets X. Systemic effects of chronic obstructive pulmonary disease. Eur Respir J2003; 21(2):347360.DOI:10.1183/09031936.03.00405703.

11. Gabay C, Kushner I. Acute-phase proteins and other systemic responses to inûammation. $\mathrm{N}$ Engl J Med1999; 340(6):448-454.DOI:10.1056/ NEJM199902113400607.

12. World Medical Association. World Medical Association declaration of Helsinki ethical principles for medical research involving human subjects. JAMA 2013; 310(20):2191-2194 [Internet] [Cited April 18, 2019]. Available from: http://jama.jamanetwork.com. DOI:10.1001/jama.2013.281053.

13. Hajian-Tilaki K. Receiver operating characteristic (ROC) curve analysis for medical diagnostic test evaluation. Caspian J Intern Med 2013; 4(2):627-635. PMID:24009950.

14. Golpe R, López PS, Jiménez EC, Añón OC, Pérez-deLlano L. Distribution of clinical phenotypes in patients with chronic obstructive pulmonary disease caused by biomass and tobacco smoke. Arch Bronconeumol2014; 50(8):318-324. DOI:10.1016/j.arbres.2013.12.013.
15. Golpe R, Martín-Robles I, Sanjuán-López P, Pérezde-Llano L, González-Juanatey C, López-Campos JL, Arellano-Orden E. Differences in systemic inflammation between cigarette and biomass smokeinduced COPD. Int J Chron Obstruct Pulmon Dis2017; 12:2639-2646. DOI:10.2147/COPD.S141068.

16. Terashima T, English D, Hogg JC, van Eeden SF. The release of polymorphonuclear leukocyte from the bone marrow by interleukin 8. Blood1998; 92(3):10621069.PMID:9680376.

17. Kobayashi S, Hanagama M, Yamanda S, Ishida M, Yanai M. Inflammatory biomarkers in asthma-COPD overlap syndrome. Int J Chron Obstruct Pulmon Dis 2016; 11(1):2117-2123. DOI:10.2147/ COPD.S113647.

18. Takayama Y, Ohnishi H, Ogasawara F, Oyama K, Kubota T, Yokoyama A. Clinical utility of fractional exhaled nitric oxide and blood eosinophils counts in the diagnosis of asthma-COPD overlap. Int J Chron Obstruct Pulmon Dis 2018; 13:2525-2532. DOI:10.2147/COPD.S167600.

19. Larché M, Robinson DS, Kay AB. The role of T lymphocytes in the pathogenesis of asthma. J Allergy Clin Immunol 2003; 111(3):450-463. DOI:10.1067/ mai.2003.169.

20. Barnes PJ. Inflammatory mechanisms in patients with chronic obstructive pulmonary disease. J Allergy Clin Immunol 2016; 138(1):16-27.DOI:10.1016/ j.jaci.2016.05.011

21. Robinson D, Humbert M, Buhl R, Cruz AA, Inoue H, Korom S, Hanania NA, Nair P. Revisiting type 2-high and type 2-low airway inflammation in asthma: current knowledge and therapeutic implications. Clin Exp Allergy 2016; 47(2):161-175. DOI:10.1111/cea.12880.

22. Okeh UM, Okoro CN. Evaluating measures of indicators of diagnostic test performance: fundamental meanings and formulars. J Biomet Biostat 2012; 3(1):132(1-10). DOI:10.4172/2155-6180.1000132. 